\title{
Influence of Organization Management on Systems of Performance Measurement and Management Control
}

\section{Zora Říhová}

\begin{abstract}
This article is focused on investigating the influence of organization management on Performance Measurement Systems (PMS) and Management Control Systems (MCS). The goal of the paper is to draw attention to the fact that designing PMS the validity of which could not be disputed, needs to correctly determine the organization structure and the role competences. In the example of matrix structures are shown some of the difficulties that may distort the results obtained from these systems. PMS + MCS is to be created after a thorough critical analysis of the organizational structure and set competences.
\end{abstract}

Keywords: Organizational structure, System aspects of organizational structure, Matrix structure, Performance measurement systems, Management control systems.

\section{Introduction}

Performance Measurement Systems (PMS) and Management Control Systems (MCS) are important systems for the measurement of company performance. The company's performance is substantially given by a positive response and long-term (contentment) of customers.

There is an extensive amount of research going on in the direction of PMS. Many papers concern the PMS in business and management, e.g. (Bititci et al., 2005; Bititci, et al., 2012), or from the perspective of business process management (Pádua, Jabbour, 2015) and also in public management (Boyne, et al, 2009).

This paper is focused on investigating the influence of organization management on PMS and MCS. The goal of the paper is to draw attention to the fact that designing PMS the validity of which could not be disputed, needs to correctly determine the organization structure and the role competences.

Systems PMS + MCS are thus used for two main purposes:

- Improve customer related orientation.

- Increase the effectiveness and performance of the company.

\footnotetext{
* Department of Systems Analysis, Faculty of Informatics and Statistics, University of Economics, Prague, nám. W. Churchilla 4, 13067 Praha 3, Czech Republic 
The orientation of all activities toward the customer, however, is often a problem, and attention is focused on the correct functioning of the company and its refinement in terms of communication, personal, financial, culture.

Given that PMS + MCS basically must always correspond to any organizational structure, it is necessary to know the organizational structure of the company. Even the best controlling systems that do not reflect the organizational structure are based exactly on the fact that we have good results from non-relevant documentation. It is therefore necessary before the formation of PMS and MCS to analyze the organizational structure of the company.

First of all it should be examined whether the organizational structure, which requires a PMS + MCS system, corresponds to the above requirements. It means whether it is sufficiently customer-oriented and if it is possible to obtain relevant data to assess the performance and effectiveness.

This seemingly trivial argument can be well demonstrated in concrete cases. One of the recommended (more in theory) arrangements is a matrix organizational structure. From a brief analysis of this form we shall try to demonstrate the thesis of the importance of analyzing the organizational structure when creating PMS + MCS. It can be based on the results of the survey (Pilzová, 2010), which addressed the strengths and weaknesses of the matrix arrangement in terms of company managers in the Czech Republic. Also author's practical experience in information systems implementing (Information system SAP in years 1996-2013) confirms that it is impossible to establish efficient and correct indicators without a detailed analysis of the organizational structure and examining weaknesses.

\section{Theoretical framework for critical discussion of difficulties in organization structure}

Before we proceed to discuss the difficulties in organization structure related to PMS + MCS (in the Section 3), it is useful to introduce at least key concepts from organization theory and the process of organizing.

Inefficient arrangements in organizations have great consequences, among which most often include: bureaucracy, unresolved power and responsibility, delaying of the decision-making process, the emergence of conflicts, late or incorrect responses in the event of internal and external business activities, and a disproportionate cost of operations (Vodáček, Vodáčková, 2005).

\subsection{Organizational structure}

The word organization is used in the sense of the organization as a company, firm, and also as an organizational structure in terms of the inner product. Organizational structure can be defined as a formal system of tasks and relationships of subordination and superiority, which manages, coordinates and motivates workers (Dědina, Odcházel, 2007, p. 134). Today, this term is understood as departmental organizational structure, and process, but also as modern association of organizations into strategic alliances or virtual teams and organizations (Dědina, Odcházel, 2007, p.16). Individual elements of the organization act back on its system and also affect behavior and other elements of the system and thus contribute to selforganization. Organization theory deals with the clarification of the principles and possibility of arrangement of the elements and their linkages and implications for the behavior of the system. 
The fundamental questions of the formation of the organization (Picot et al., 2012) are:

- Formal and informal structure - the formal structure is specifically established relationships which are grounded in formal rules (eg. Organizational Regulations). Informal organization includes spontaneous relationships between people and complements the formal structure.

- Processes and relationships - organization linked to the formal structure defines long-term relationships.

- Differentiation and Integration - regulates the division of labor, both vertically and horizontally while integration acts as a coordination and arrangement of the whole.

Organizational structure therefore organizes relationships; addiction behavior defines the behavior of parts of a whole and supports the business strategy. It is necessary to examine the question of how to meet the requirement of organizational structure for rapid and active response in favor of the customer.

Organizational structures respect the objectives of the organization, organizational tools and marginal conditions ( ̌́íhová, 1996). The goal of organization (C) is related to marginal condition $(\mathrm{P})$ and structural variable $(\mathrm{S})$ :

Where $\mathrm{P}$ are not influenceable marginal conditions determined by:

- Company environment - not only global as social, legal, technical, environmental, but also as competition, technology development and customer structure.

- The internal situation of the company in the past (as company age, tradition, development stage, way of establishing), in the present (size company, legal form, ownership, level of informatics) and the future (strategies).

- Employees that are available.

- Characters of the task as structuring (possibility of spreading to a clear process of follow-up), variability (predictable changes in prices, quality, quantity, frequency), volume (the number or amount in time) and similarity of the task.

Structural variables (S) are based on an analysis of work roles and the organizational tools:

- Specialization of task - verticals, by products.

- Allocation of responsibility and competence - different types of organizational structures.

- Process structuring and standardization as task progress, the framework conditions, results programming etc.

- Job or roles creation.

The basic formula $\mathrm{C}=\mathrm{f}(\mathrm{S}, \mathrm{P})$ answers questions about which targets $(\mathrm{C})$ the organization has to fulfill (flexibility, productivity, profits, satisfaction of needs of people), what organizational tools (S) has the company available to influence the running of the company and what conditions (P) are uncontrollable. The structure of the company thus creates a framework within which to implement the goals and objectives of a particular group of people to build and maintain linkages, that due to the vicinity, ensure the prosperity of the organization (Ř́hová, 1996). 


\subsection{Creation of organizational structure}

Organizational structures are of different types - flat, steep, linear, functional and matrix and others. This distinction is also sometimes called the "viewpoint competence and responsibility" (Vodáček, Vodáčková, 2005). The line relationship is a vertical relationship between superiors and subordinates. It is the oldest relationship in which the command is passed from top to bottom, single-level management. Efforts to be better suited to the organizational structure are reflected in the structuring of product, geography, by market and under.

In practice, they are rarely applied as purely one type of structure. Most of these are combinations and the most frequent variant combinations are linearly staff or target programming (Vodáček, Vodáčková, 2005). For the second variant, we also classify different types of matrix organizational structures. Matrix structures include more complex hierarchical systems, which can be multiple. Sometimes it is only a short-term status (defined timescale of the project), but may also continue for a long time. Matrix organizational structure is used especially for large businesses or multinational corporations as a customer-organized structure.

The functioning of the matrix structure is mostly based on the management structure in terms of geography, with offices in different countries, which are managed by local country managers (with its own budget in each country) and multinational divisional managers, who are responsible for product specialization (government, industry, energy, telco, commerce, etc.) and have a budget for these divisions. Divisions are mostly represented in local offices and are subject to management at all levels - e.g. Trade - a local branch CZ, office for Middle Europe, Central Europe (Middle + Germany), a pan-European management, EMEA (Europe + Middle East + Africa), CEO. Also CZ are subject to direct managing of Finance and Human Relations (HR) on the high level. Fig. 1. 


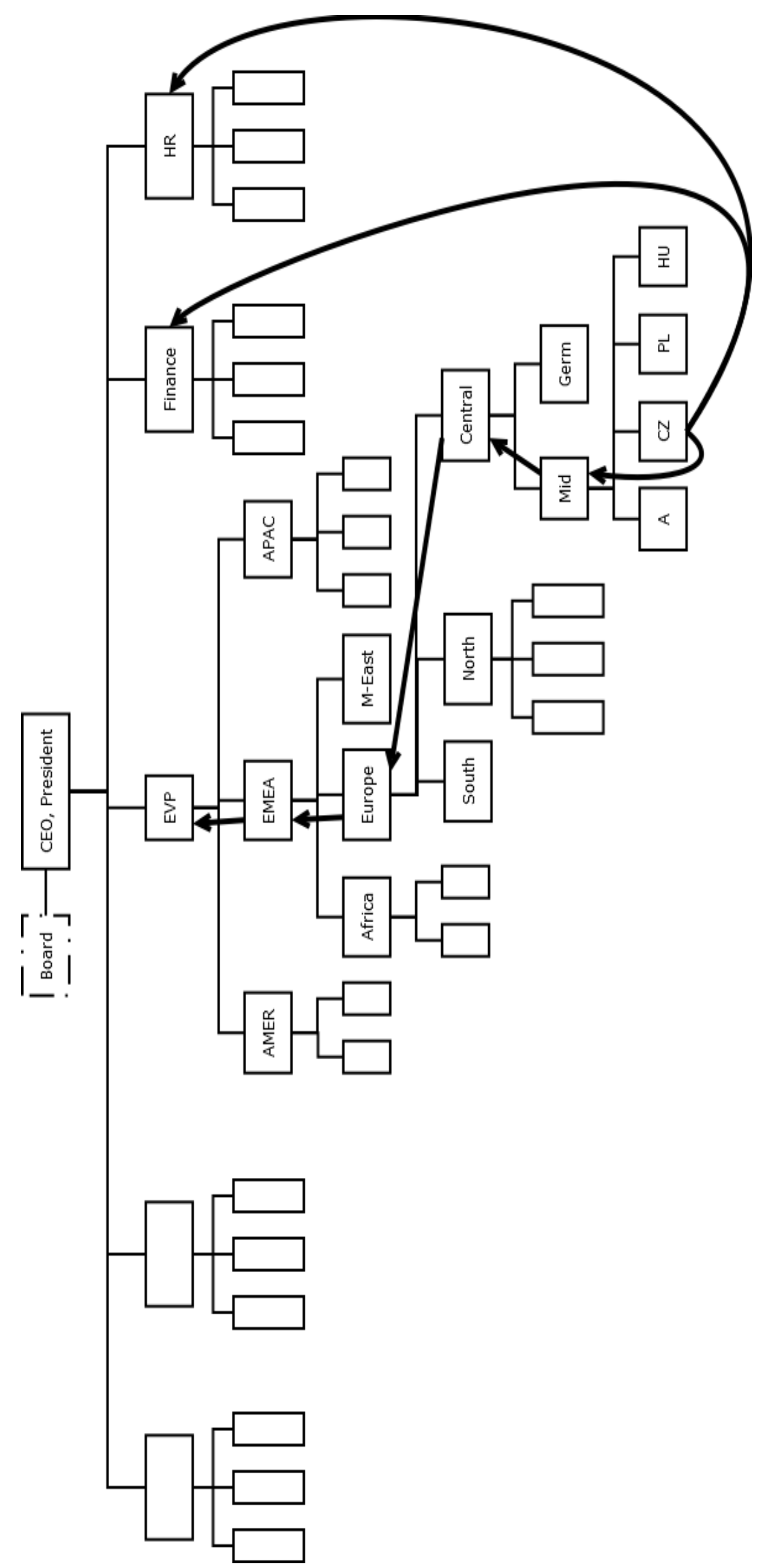

Fig.1. Geography matrix structure with multinational divisional managing. Source: Author 
IT companies may be more structurally divided into divisions of software, hardware, servers, services, outsourcing, etc. In contrast, for example, the Finance Division is managed centrally and reports directly to headquarters. For IT companies it is broken down on the vertical divisional level, representing the different product specialization (hardware, servers, etc.). The horizontal structure is broken down in terms of sectors (Finance, Public, Global Business, etc.). The third dimension is the territorial aspect - the geographical breakdown. In terms of management levels it can go up to five levels of management.

\section{Discussion}

In several examples (not an exhaustive list) from the author's own experience and from survey (Pilzová, 2010) we show the complexity of the issue and matrix organizational structure with respect to the determination of PMS + MCS.

\subsection{Several decision-making subjects}

The matrix structure does not contain only the double linkages, but additionally it may concern the project teams what results in multiple and complex linkages across the whole organization. Consequently, it is connected to the level of management with given competences. Each decision making subject may have other preferences, rules, and may complicate the creation of PMS + MCS so as to ensure adequate impact assessment decisions. The decision may be in conflict with the interests of the level at which the problem originated (some level of management assesses the importance of the problem differently than, for instance the republican level) or the decision was made late due to a lengthy decision-making process. In this situation it is difficult to make a simple, true and correct system of indicators.

\subsection{Multiplicity reporting}

From the organizational structure and more decision-making places, there is the obligation of reporting on several senior positions, which can be very stressful for employees. There can also be various reporting systems and they may use different indicators for the same reporting aspect or conversely the same pointers to more examined activities. Decision points can then attach a different weight to the reported indicators. It is therefore necessary to establish a PMS + MCS with a view to optimizing indicators and regular reports processed.

\subsection{Unclearly specified competences}

It is a problematic area and measuring the performance of employees / departments / divisions, where it may be unclear to what extent can affect the performance of the entire organization. Often they do not even realize what goals the organization has and how it relates to the objectives of the employee or department. And the question is therefore how to define indicators of the workplace. Someone is focused on performance, someone on some type of profit, and may not be obvious what is important for the parent level.

Unclearly specified powers and responsibilities may enable prioritization of local optima before optimum whole. Moreover, it criticized ambiguous responsibility between roles and superiority. This problem is also related to the emergence of the endless "space" that is difficult to control, and many employees could be demotivating. This area therefore should be considered before introducing systems PMS + MCS. 


\subsection{Contradictory interests of close cooperating subjects}

From the vaguely specified competencies it implies the possibility of different preferences in activities of the institutions of the company. Workers local affiliates may be in an environment that creates a competitive space for internal rivalries and can negatively impact customers. The customer can be serviced by one or more account managers from one company. Individual account managers are evaluated for the amount budgeted to their division, and their motivation is to get the largest share of the total investment budget. Thus, to ensure optimum customer needs may not be their main concern.

The final budget and the related services offer depend more on the business and communication skills of a particular account manager, rather than on the real needs of the customer. The same problem occurs if the company performs for multiple account managers who prioritize their own interest before the interest of the customer. It is therefore a contradictory interest and the question is, how do we define PMS + MCS indicators and select the right data? It is possible to assume that there are conflicting interests and there are various different data important for individual subjects and it is therefore difficult to determine which data to select and how to evaluate it, especially in relation to the customer.

Another example illustrates the various interests of the longer-term implications of a particular decision. A trader can have a clear understanding of customer needs. Purchasing divisions, however, prioritize their own target - business spending - and then take a cheaper but less convenient product. In the short term, it could be that the manager of the purchasing department is satisfied with his decision, because he managed to show lower expenses. In terms of the long-term, however, this decision proved to be unfortunate, and it had been for all the divisions that were forced to deal with the arisen shortage. A bad purchase also featured a great risk of loss of customer confidence, and risk in damaging the brand image. Purchasing divisions find themselves in practice in organizational conflicts quite often. The question therefore is what is the relevant indicator in the system PMS + MCS. Whether it is the immediate effect of reducing cost as an advantage or customer dissatisfaction, which is reflected as a negative as the decline in sales even for a longer period. The question is, who will assess it and how are these contradictory data reflected in the company's activities.

Conflicts arising in the business divisions are usually solved by their managers. Then it depends on communication skills and abilities of individual managers. For example the business manager must be able to convince his colleagues that the implementation of the new solution is really needed and must be able to explain what impact it has on customers. Otherwise, the manager responsible for the purchasing division must be able to explain the situation to others in the company, why it is for instance not possible on such a scale to spend resources.

A similar problem with a problematic impact on PMS + MCS can also arise at the level of the human resources department if you do not pursue the best staff, which the company may not have enough resources to pay. It does not address only the issue of salaries and bonuses for employees, but also their number. The personnel department, along with the finance department must decide whether it is better for the company to accept a worker's salary or split between two less-skilled workers. Furthermore, how to reflect similar decisions to the controlling system in the short and long term. In such cases it is necessary to consider the enterprise-wide scale, and to assess the real needs of the organization. 


\subsection{Other possible aspects of the impact of organizational structures on PMS+MCS}

From the perspective of organizational structures on systems PMS+MCS include also some others aspects:

- Divergence of interests of close associates

- Conflict in valuation of larger contracts - the decision-making process can be very lenghty

- Favoring an optimum before a maximum

- A large number of complex relationships and links

- Ignoring the customer's perspective

- The effect of cultural influences in multinational corporations.

\section{Conclusion}

Creating PMS + MCS is very important, but must be based on what we need: customer-oriented systems, based on the correct system and also use the true and relevant data. Data reality in systems PMS + CMS often generates information outputs based on input data from lower management levels that are overloaded by operativecontrol and antisense contradictory requirements of different various higher decision-making subjects.

Then, they do not have left much time, strength and energy to investigate the truthfulness of reported data. Other levels of management then build on these data further analyses and reports for the other higher levels of the management. These often irrelevant data are transmitted to the next levels in well arranged tables. This increases the difference between the theoretical point of view of idealistic systems PMS + CMS and the real life of people in the organizational structure.

The division of labor enforces organizing people, provides the framework and space in which to realize objectives and goals of the company. In the example of matrix structures it was shown that MCS + PMS systems need to be created after a thorough critical analysis of the organizational structure and set of powers. We need to measure what has some meaning to the organization (focus, goals, status, how it is focused on customers). The created systems PMS + CMS must be individually designed for the specific organization.

The requirement of effectiveness of the organizational structure in relation to the customer and sales efficiency is essential and serves to maintain a closer relationship with the customer. It is impossible to establish efficient and correct indicators without a detailed analysis of the organizational structure and examining weaknesses. Each decision making subject may have other preferences, rules, competences and may complicate the creation of PMS + MCS so as to ensure adequate impact assessment decisions. To conclude, the paper contributes to the complex view of the problems associated with designing PMS + CMS systems.

\section{References}

Bititci, U. S., Mendibil, K., Martinez, V., \& Albores, P. (2005). Measuring and managing performance in extended enterprises. International Journal of Operations and Production Management, 25(4), 333-353

Bititci, U. S., Garengo, P., Dörfler, V., \& Nudurupati, S. (2012). Performance Measurement: Challenges for Tomorrow. International Journal of Management Reviews, 14(3), 305-327. 
Boyne, G. A., Meier, K. J., O'Toole, L. J. and Walker, R. M. (2006). Public management and organizational performance: An agenda for research. In Boyne, G.A., Meier, K.J., O’Toole, L.J. and Walker, R.M. (eds). Public services performance: Perspectives on measurement and management (pp. 295-311). Cambridge: University Press.

Dědina, J., \& Odcházel, J. (2007). Management a moderní organizování firmy. Prague: Grada.

Pádua, S.I.D, \& Jabour, C.J.C. (2015). Promotion and evolution of sustainability performance measurement systems from a perspective of business process management. Business Process Management Journal, 21, 403-418.

Picot, A., Dietl, H., Franck, E., Fiedler, M., \& Royer, S. (2012). Organisation - Theorie und Praxis aus ökonomischer Sicht. Stuttgart: Schäffer-Poeschel.

Pilzová, H. (2010). Zákaznicky orientovaná organizační struktura společnosti. Diploma thesis. Prague: VŠE, Praha.

Říhová, Z. (1996). Informační zabezpečení a organizační změny. Prague: VŠE, Praha.

Vodáček, L., \& Vodáčková O. (2005). Management, teorie a praxe v informační společnosti. Prague: Management Press. 
